\title{
Optimal Sizing of a Wind-Photovoltaic-Battery Hybrid Renewable Energy System Considering Socio-demographic Factors
}

\author{
S. R. Tito, T. T. Lie and T. N. Anderson \\ School of Engineering, Computer and Mathematical Sciences \\ Auckland University of Technology, New Zealand
}

\begin{abstract}
The sizing of a stand-alone wind-photovoltaic-battery hybrid renewable energy system (HRES) is greatly influenced by socio-demographic factors however, few studies have examined how sociodemographic factors, as borne out by different electrical usage patterns, influence the size of HRESs.

This paper investigates how these factors influence the optimal sizing of a stand-alone HRES using a hybrid optimization method to match the available renewable energy with the demand. In this regard, different energy usage patterns resulting from users socio-demographic profile have been investigated and used for the optimal sizing of a HRES. The results show that the electricity usage profile of a site has a significant impact on the sizing and design of the system. Further, the results illustrate that one can design a system that meets the demand profiles resulting from socio-demographic factors with a minimum unmet load; however, by optimizing systems to the users socio-demographic profile, significant cost savings can be made.
\end{abstract}

Keywords-hybrid renewable energy system, stand-alone, sizing, socio-demographic factors, load profile 


\section{Nomenclature:}

HRES: Hybrid Renewable Energy System,

GA: Genetic Algorithm,

PV: Photovoltaic,

WG: Wind Turbine Generation,

LPSP: Loss of Power Supply Probability,

DC: Direct Current,

AC: Alternating Current,

STC: Standard Test Conditions,

SOC: State of charge,

$\mathrm{P}_{\mathrm{r}}$ : rated power,

$\mathrm{v}_{\mathrm{ci}}$ : cut in speed of wind turbine,

$\mathrm{V}_{\mathrm{r} \text { : }}$ rated speed of wind turbine,

$\mathrm{v}_{\mathrm{co}}$ : cut-out of the wind turbine

$\alpha$ : Power law exponents

$\eta_{W G:}$ Efficiency of the wind turbine generator
$\eta_{P V}$ : Efficiency of the PV module and converter,

$\mathrm{N}_{\mathrm{S}}$ : Number of PV-modules connected in series,

Ns: Number of PV-modules connected in Parallel,

$\mathrm{C}_{\text {bat }}$ : capacity of a battery,

$\eta_{b a t .}:$ Battery charge Efficiency,

$\beta$ : photovoltaic tilt angle

G: Global solar irradiance, $\mathrm{W} / \mathrm{m}^{2}$,

NOCT: Nominal Operating Cell temperature,

$\mathrm{T}_{\mathrm{c}}$ : cell temperature, ${ }^{\circ} \mathrm{C}$,

FF: Fill factor, 
From extensive research, photovoltaic (PV) and wind turbine generation (WG) technologies have been developed to such an extent that they can compete as an economical alternative to conventional power generating systems. However, the inconsistent nature of their output makes them unpredictable and costly sources of power when they are used alone, thus necessitating the development of stand-alone hybrid renewable energy system (HRES). In these systems, a battery bank is usually used as a backup power supply to satisfy demand when energy from the renewable sources is not sufficient. The complementary production capabilities of PV and WG enable the weaknesses associated with each to be overcome, and hence reduce the size of these storage devices. Moreover, a wind-PV-battery system is considered as one of the most commercially viable configurations of HRES (Deshmukh and Deshmukh, 2008) .

An optimum mix and selection of each HRES device is crucial in order to make a wind-PV-battery system reliable and cost effective. In addition, the non-linear system characteristics, the transient user demand and the variable generation from WG and PV-modules makes the size optimization of a HRES complicated. Therefore, an optimization method that matches the energy generation with the demand of a site needs to be applied to ensure the lowest investment with adequate and full use of resources.

Among the many optimization methods, the exhaustive search method and genetic algorithms (GA) have been widely investigated. In numerous studies the exhaustive search method was used for sizing a WG, PVmodules and batteries for a desired reliability index, typically the loss of power supply probability (LPSP) (Ai et al., 2003; Borowy and Salameh, 1996, 1994; Diaf et al., 2008; Kaabeche et al., 2011; Kellogg et al., 1998; Yang et al., 2007).

In a study by (Zhou et al., 2010) a number of different combinations of devices were checked for a desired LPSP either by linearly changing the corresponding decision variables or by employing linear programming techniques. The combination delivering the lowest total cost was considered as the optimum for a given demand. However, in doing so two important parameters, PV module slope angle and WG installation height, were not considered as they greatly increased the number of iterations. 
To overcome the time associated with reaching an optimum solution by exhaustive search means, numerous researchers have looked to the use of heuristic methods such as genetic algorithms (GA). In this regard genetic algorithms, were introduced in Koutroulis et al. (2006), in Yang et al. (2008), in Tégani et al., (2014) and in Gupta et al., (2012) for the optimal sizing of a HRES while Hong et al., (2012) made use of a Markov-based GA for sizing a stand-alone power system consisting of wind, PV and a diesel generator. More recently González et al., (2015) made use of GA for optimizing a grid connected hybrid system consisting of photovoltaics and wind.

Given the increased speed with which GA's can converge to an optimum configuration (though they still require large numbers of iterations to identify a global optimum) these studies included both WG installation height and PV-module tilt angle in their optimization. Now, despite the work that has gone into the development of new optimization methods and studies examining the optimization of HRES systems, few studies have examined how the demand placed on such systems impacts their size.

In particular the load profile of a site is of great importance as it dictates the size of the system components, however, for many applications (particularly residential dwellings) this load is often stochastic in nature and governed by a wide range of internal and external factors such as the socio-demographic characteristics of the households' occupants and also seasonal variations (Stoecklein et al., 2001).

In a number of previous studies examining the optimal size of a HRES, the average hourly load profile of a day, or monthly average daily load, was repeated throughout the year to determine the optimum (Ma et al., 2014; Rouhani et al., 2013). Similarly, in Baniasad Askari et al. (2014) the monthly average daily demand profile was considered, however the temporal position of peak demand in the profile remain fixed. In a similar vein, Aissou et al. (2015) considered only the average energy consumption of an application in when sizing a wind-PV-battery hybrid system. In doing this, all the approaches do not consider the impact of sociodemographic factors, borne out as a variation in the temporal distribution or magnitude of loads that occur in reality.

Given the potential variation in electricity demand, as a function of the socio-demographics of a household, Stoecklein et al. (2001) undertook a wide ranging study of household electricity use in 40 New Zealand 
houses. In this they noted that the demand profile of a site could be classified into six different types of electricity users, as a result of the socio-demographic factors and seasonal variation. In this work, the average hourly load profiles of each of these six socio-demographic groups are investigated and the optimal sized system for each type of user is suggested.

\section{SYSTEM MODELLING}

To determine the optimal size of the HRES for each socio-demographic user group a generic WG-PVbattery HRES was modelled (as shown in Fig.1) for operation across a full year in Auckland, New Zealand (latitude $36.85^{\circ} \mathrm{S}$ and longitude $174.78^{\circ} \mathrm{E}$ ). As the input for the optimizations, typical meteorological year (TMY) data for Auckland, was obtained from the Department of Energy EnergyPlus weather files (Department of Energy, 2013). In addition, WG, PV-module and batteries with the specifications given in Tales 1-3 were used in the analysis.

TABLE 1. SPECIFICATION OF THE WG

\begin{tabular}{|c|c|c|c|c|}
\hline Power & $\mathbf{h}_{\text {low }}$ & $\mathbf{h}_{\text {high }}$ & WG Capital. Cost & Tower Capital Cost \\
$(\mathbf{W})$ & $(\mathbf{m})$ & $\mathbf{( m )}$ & $\mathbf{( \$ )}$ & (\$/per unit length) \\
\hline 1000 & 11 & 35 & 2400 & 55 \\
\hline
\end{tabular}

TABLE 2. SPECIFICATION OF THE PV-MODULE

\begin{tabular}{|c|c|c|c|c|c|}
\hline$V_{\text {oc }}(\mathbf{V})$ & $\mathbf{I s c}_{\mathbf{s}}(\mathbf{A})$ & $\mathbf{V}_{\max }(\mathbf{V})$ & $\mathbf{I}_{\max }(\mathbf{A})$ & $\mathbf{P}_{\max }(\mathbf{W})$ & Capital. Cost (\$) \\
\hline 64.8 & 6.24 & 54.7 & 5.86 & 320 & 640 \\
\hline
\end{tabular}

TABLE 3. SPECIFICATION OF THE BATTERY

\begin{tabular}{|c|c|c|}
\hline $\begin{array}{c}\text { Price } \\
\mathbf{( \$ )}\end{array}$ & $\begin{array}{c}\text { Voltage } \\
(\mathbf{V})\end{array}$ & $\begin{array}{c}\text { Capacity } \\
(\mathbf{A h})\end{array}$ \\
\hline 1239 & 12 & 357 \\
\hline
\end{tabular}


To simplify the system modelling, the WGs, PV-modules and batteries were considered to be connected to DC and AC loads through a 24V DC bus (Tito et al., 2013) with the characteristics of each component discussed in the following sub-sections.

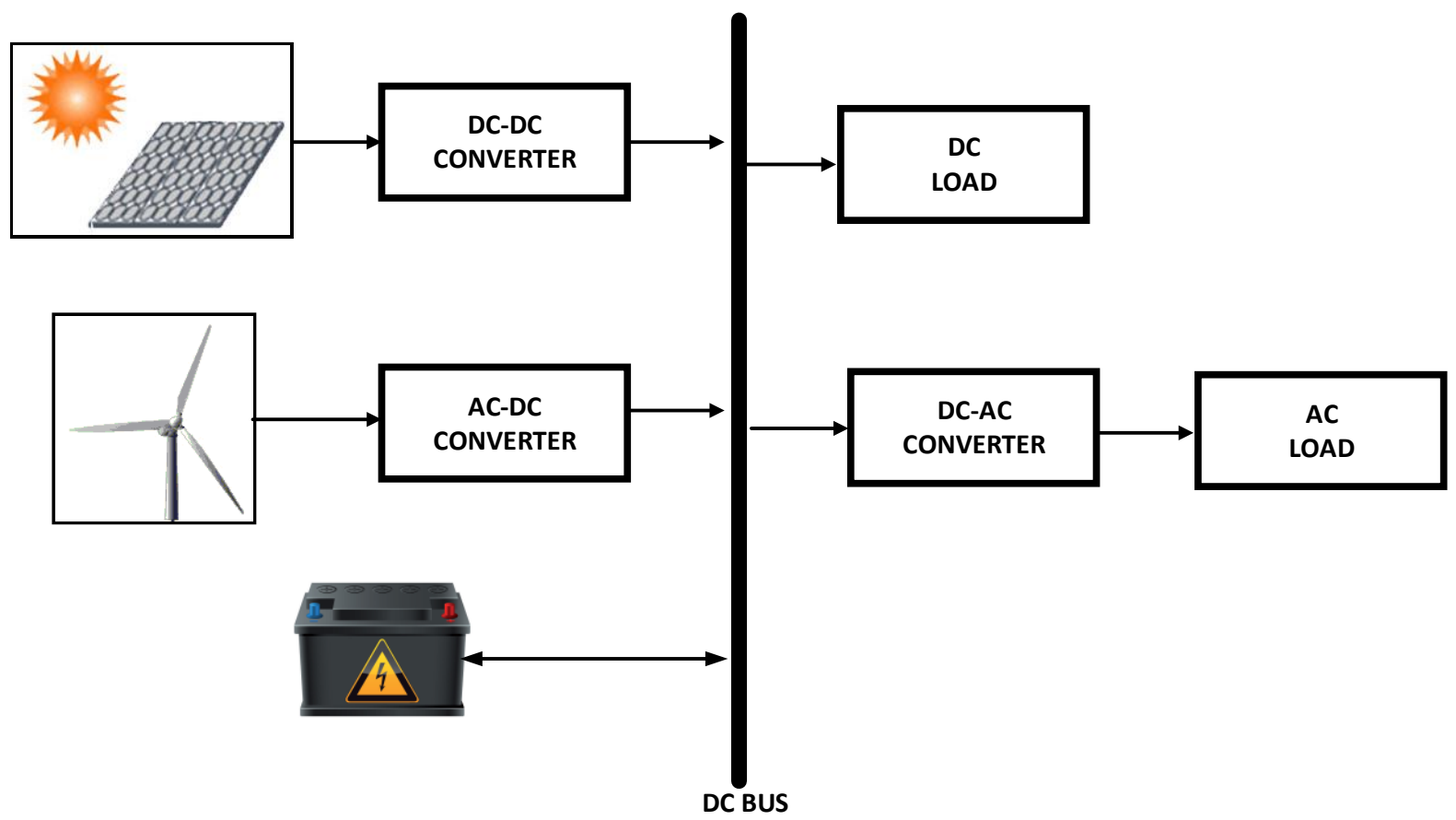

Fig. 1: A WG-PV-Battery hybrid renewable energy system

\subsection{Wind turbine generating (WG) model}

The wind speed of a site determines the specific power output, $P_{w}\left(\mathrm{~W} / \mathrm{m}^{2}\right)$ from a WG and the relation can be expressed by equation (1) (Chedid et al., 1998).

$$
\begin{aligned}
& P_{w}(t)=0 \quad v(t)<v_{c i} \\
& P_{w}(t)=a v^{3}(t)-b P_{r} \quad v_{c i} \leq v(t)<v_{r} \\
& P_{w}(t)=P_{r} \quad v_{r} \leq v(t)<v_{c o} \\
& P_{w}(t)=0 \quad v(t) \geq v_{c o}
\end{aligned}
$$

where, $a=\frac{P_{r}}{\left(v_{r}^{3}-v_{c i}^{3}\right)}, v(t)$ is the wind speed at an hour $t, b=\frac{v_{c i}^{3}}{\left(v_{r}^{3}-v_{c i}^{3}\right)}, P_{r}$ is the rated power, $v_{c i}, v_{r}$ and $v_{c o}$ are the cut-in, rated speed and cut-out of the wind turbine respectively as provided by the manufacturer of the selected turbine (Tito et al., 2013). 
Now the hourly wind speed at a reference height of $33 \mathrm{~m}$ is given in the EnergyPlus weather files (Department of Energy, 2013) and subsequently, the wind speed at any height can be calculated using equation (2) (Patel, 1999).

$$
v_{h}=v_{r}\left(\frac{h}{h_{r}}\right)^{\alpha}
$$

where, $v_{h}$ and $v_{r}$ are the wind speed at the hub height, $h(\mathrm{~m})$ and the reference height, $h_{r}(\mathrm{~m})$ respectively and $\alpha$ is power law exponent, taken to be $1 / 7$ for open space (Borowy and Salameh, 1996). As such, the actual electrical power from a WG can be found by equation (3).

$$
P_{W G}=P_{w} A_{W G} \eta_{w G}
$$

Where $\eta_{W G}$ is the efficiency of the wind turbine generator and corresponding converters and $A_{W G}$ is the total swept area of the WG.

\subsection{Photovoltaic module model}

The maximum output power of a PV array at any time on a day is calculated using the PV module specifications provided by the manufacturer and it can be expressed by equation (4) (Koutroulis et al., 2006):

$$
\begin{aligned}
& P_{P V}(t, \beta)=N_{S} \cdot N_{P} \cdot V_{O C}(t, \beta) \cdot I_{S C}(t, \beta) \cdot F F(t) \\
& V_{O C}(t, \beta)=\left\{V_{O C-S T C}-K_{V} T_{C}(t)\right\} \\
& I_{S C}(t, \beta)=\left\{I_{S C-S T C}+K_{I}\left[T_{C}(t)-25^{\circ} C\right]\right\} \frac{G(t, \beta)}{1000} \\
& T_{C}(t)=T_{A}+\left(N O C T-20^{\circ} \mathrm{C}\right) \frac{G(t, \beta)}{800}
\end{aligned}
$$

where $V_{O C}(t, \beta)$ is the PV-module open circuit voltage $(\mathrm{V})$ at hour $t, I_{S C}(t, \beta)$ is the PV-module short circuit current (A) at hour $t, F F(t)$ is the fill factor of hour $t, V_{O C-S T C}$ is the open circuit voltage under STC (V), $K_{V}$ is the open circuit voltage temperature coefficient $\left(\mathrm{V} /{ }^{\circ} \mathrm{C}\right), I_{S C-S T C}$ is the short-circuit current under standard test conditions (STC) (A), $K_{I}$ is the short-circuit current temperature coefficient (A/ $\left.{ }^{0} \mathrm{C}\right), T_{C}(t)$ is the instantaneous cell temperature in $\left({ }^{\circ} \mathrm{C}\right)$, NOCT is the nominal operating cell temperature, $G(t, \beta)$ is the global solar irradiance $\left(\mathrm{W} / \mathrm{m}^{2}\right)$ incident on the $\mathrm{PV}$ module at a tilt angle of $\beta^{o}$ and $T_{A}$ is the ambient temperature $\left({ }^{\circ} \mathrm{C}\right)$ (taken from the TMY data). Thus, the total power output from a PV array is given by equation (5). 


$$
P_{\text {array }}(t, \beta)=\eta_{P V} N_{S} N_{P} P_{P V}(t, \beta)
$$

where $N_{P}$ and $N_{S}$ are the number of PV modules connected in parallel and in series respectively and $\eta_{P V}$ is the PV-module's and corresponding converter's efficiency (Tito et al., 2013). In this work, the employed sizing optimization method determines the number of parallel connections of PV modules and the number of PV modules connected in series, as defined by the bus voltage.

\subsection{Battery model}

For the optimization it is assumed that the surplus electrical energy from the WG and PV-modules is stored in lead-acid battery banks and energy is extracted from the battery when the energy generation from these renewable sources is not sufficient. The instantaneous state of charge (SOC) is usually used to determine the charging and discharging state of a battery. The instantaneous SOC of a battery can be calculated by equation

(6) (Yang et al., 2008):

$$
\operatorname{SOC}(t)=\operatorname{SOC}(t-1) \cdot\left(1-\frac{\sigma \cdot \Delta t}{24}\right)+\frac{I_{\text {bat. }}(t) \cdot \Delta t \cdot \eta_{\text {bat }} .}{C_{\text {bat. }}}
$$

Where $S O C(t)$ and $S O C(t-1)$ are the SOC at the current (t hour) and previous (t-1) hour respectively, $\sigma$ is the self-discharge rate (assumed to be $0.2 \%$ per day) and $C_{\text {bat }}$ is the capacity of a battery. The battery charge efficiency $\left(\eta_{b a t}\right)$ is taken to be 0.8 and the discharge efficiency is taken to be 1 as suggested by Yang, et al. (2008). As such, the battery current of a hybrid WG-PV at any time is given by equation (7).

$$
I_{\text {bat. }}(t)=\frac{P_{P V}(t)+P_{W G}(t)-P_{\text {Load }}(t)}{V_{\text {bat. }}(t)}
$$

where $P_{W G}(t)$ and $P_{P V}(t)$ are the power generated by the WGs and the PV modules respectively at an hour $t$, $P_{L O A D}(t)$ is the demand at an hour $t$ and $V_{b a t .}(t)$ is the battery voltage at an hour $t$.

\subsection{Load profile}

As mentioned earlier, the load profile that a HRES is required to meet can have a significant influence on the sizing of the system and hence there is a need to match generation with demand for a particular location. 
Previously, Stoecklein et al. (2001), undertook extensive studies on time-of-day energy use data for forty New Zealand households with a view to determining generic daily demand profiles. Due to the considerable variation of the energy usage profile throughout the year, the analysis was conducted on monthly averagedaily profiles, thus the profiles also included the effect of seasonal variation. In this respect 239 profiles collected from these forty houses were classified using a Kohonen probabilistic neural network (Kohonen, 1989) into six different types based on the variation of the time of energy use. Fig. 2a-f shows the six demand profiles identified for use in this optimization, each of which is the average of their class.

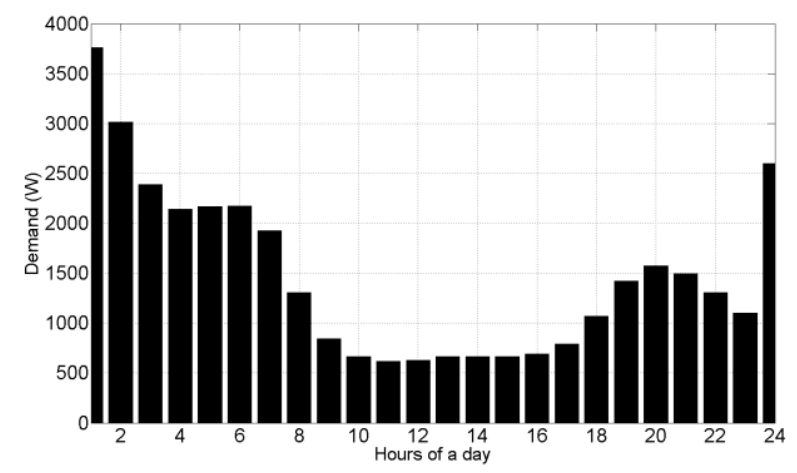

(a) High night use

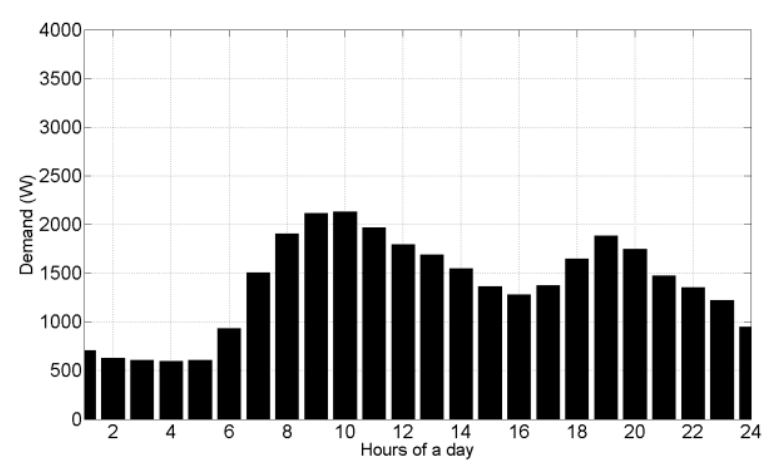

(c) Flat day use

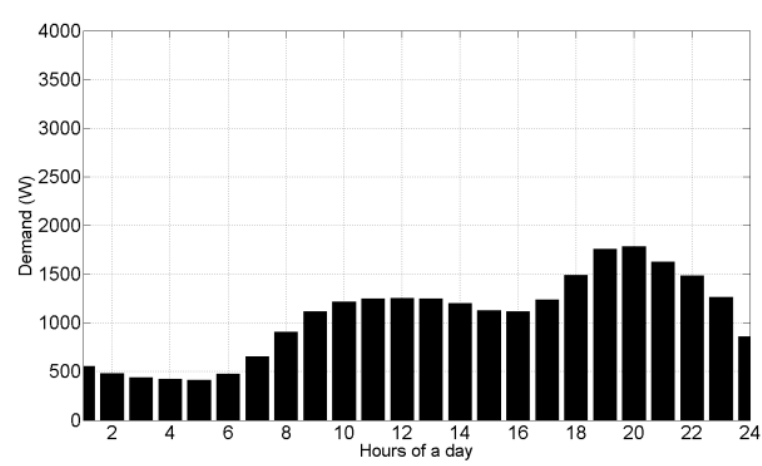

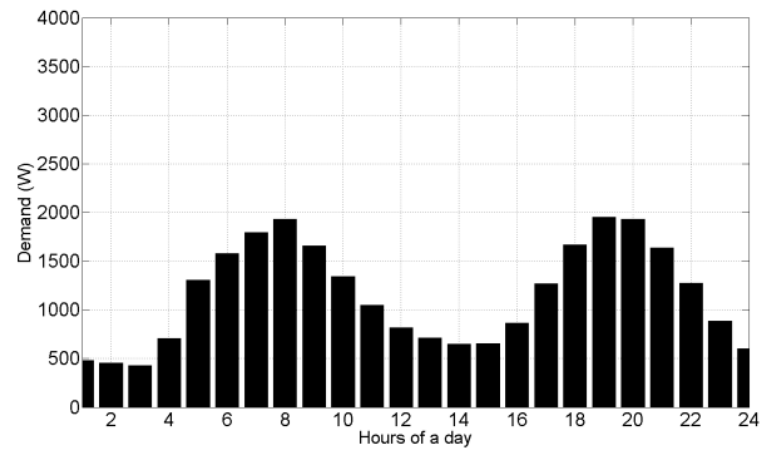

(b) Morning and evening peaks

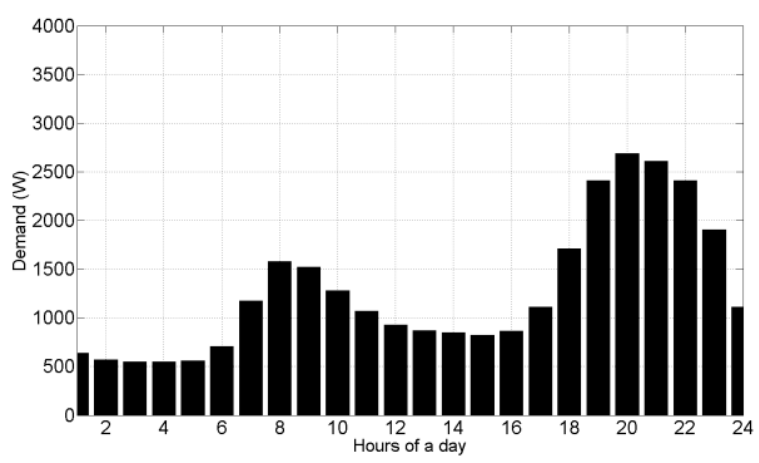

(d) Evening peak use

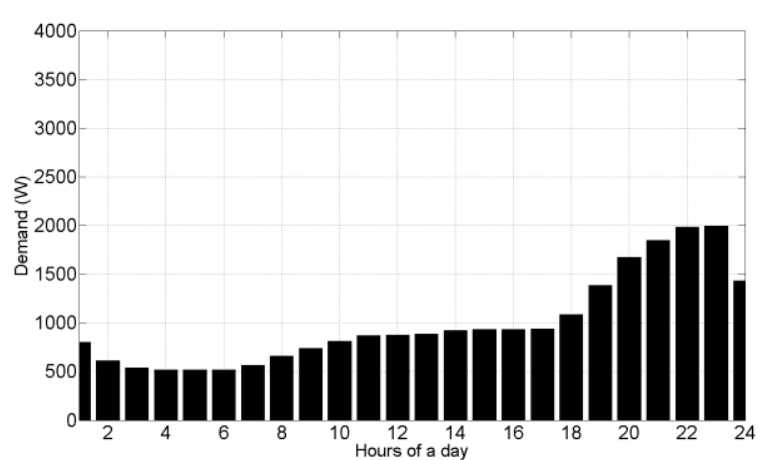


(e) Low flat use

(f) Low use with evening peak

Fig. 2a-f: Six classes of load profile

An examination of these six profiles reveals that each of them is markedly different from the others both in temporal position and amount of energy use. Based on these six classes, it is possible to illustrate the effect of socio-demographic factors and seasonal demand variations on the optimal sizing of a HRES and the size of a HRES can be optimized with these various demand profiles of a site for a zero LPSP.

\section{OPTIMISATION METHOD}

For this study, the aim was to minimize the total cost of ownership over the life of the HRES while maintaining an LPSP of zero for each class of energy user. Hence, the total cost consists of the capital cost of WGs, PV-modules and batteries, and 20 years total maintenance and operation costs, as given by the objective function shown in equation (8) (Koutroulis et al., 2006).

$$
\begin{aligned}
& \text { Minimize } f\left(N_{P V}, N_{W G}, N_{\text {bat. }}, \beta, h\right) \\
& \quad=\left[N_{P V}\left(C_{P V}+20 M_{P V}\right)+N_{W G}\left(C_{W G}+20 M_{W G}+h . C_{h}+20 h M_{h}\right)+N_{\text {bat. }}\left(C_{\text {bat. }}+y_{\text {bat. }} C_{\text {bat. }}+\right.\right. \\
& \left.\left(20-y_{\text {bat. }}-1\right) M_{\text {bat. }}\right]
\end{aligned}
$$

Subject to the constraints in equation (9):

$$
\begin{aligned}
& N_{W G} \geq 0, \\
& N_{P V} \geq 0, \\
& N_{b a t .} \geq 0, \\
& 90^{\circ} \geq \beta \geq 0, \\
& 11 \geq h \geq 35,
\end{aligned}
$$

where, $N_{P V}\left(N_{S} \times N_{P}\right)$ is the number of photovoltaic modules, $C_{P V}$ is the capital cost of a photovoltaic module, $M_{P V}$ is the yearly maintenance and operational cost of a PV module, $N_{W G}$ is the number of wind turbine generators, $C_{W G}$ is the capital cost of a WG, $M_{W G}$ is the yearly maintenance and operational cost of a WG, $N_{b a t .}$ is the number of batteries, $\beta$ is the photovoltaic tilt angle, $h$ is the WG installation height in $\mathrm{m}, C_{h}$ is the 
capital cost per unit height of a WG tower, $C_{b a t}$. is the capital cost of a battery, $M_{h}$ is the annual maintenance and operational cost per unit height of a WG tower, $M_{b a t}$ is the annual maintenance and operational cost of a battery and $y_{\text {bat. }}$ is the expected number of battery replacements during a 20 years period (Tito et al., 2013).

Now, previously it was noted that the exhaustive search technique and the GA global optimization method, require a large number of iterations in order to converge to the optimal size of a HRES. Furthermore, stochastic GA methods are unable to guarantee optimal solutions even with a large number of generations. Thus, a hybrid method was implemented and utilized for sizing a HRES throughout this work, as shown in Fig 3. The method utilizes the advantages of both GA and the exhaustive search technique there by eliminating the drawbacks associated with each individually.

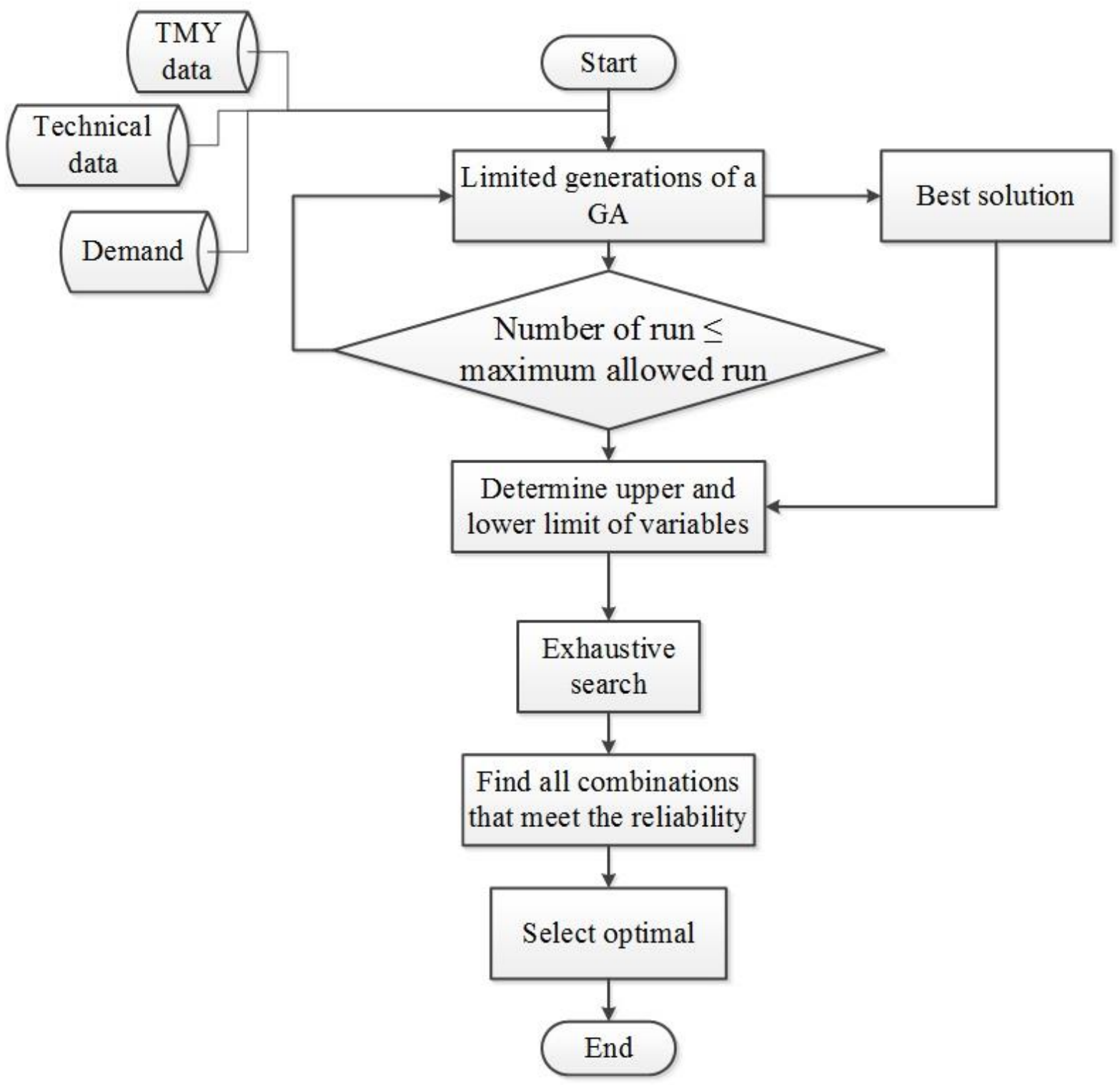


Fig. 3: Flow-chart of hybrid optimization system.

A key property of a GA is that it converges quickly to the approximate optimal solution, hence this property was exploited to define the bounds of the decision variables for an exhaustive search. To achieve this several runs of only 300 generations of a GA (Fig 4) were used, such that each run approximated the "optimal" size of a HRES and thus could be used to confine the search space. In each case, the number of chromosome was taken to be 32 , natural selection rate was 0.5 , crossover rate was 0.8 and mutation rate was 0.4 . These parameters are selected in a way to optimize the required computation time and to prevent immature convergence. The elitist technique of the crossover operation generates a new generation of chromosome from the selected solutions except the best solution of the previous generation. As the chromosomes converge quickly with lower mutation rates, the new generation of population due to the crossover operation may scatter within the limited search space and become trapped in local minima. The mutation rate was therefore kept higher so that the GAs could explore a much wider region in the search space to ensure adequate definition of the search space for the subsequent exhaustive search. The best solution in each generation was compared with the global best and any improved result was stored as a new global best. This increased the probability of reaching the global optimum solution within a reasonable number of generations.

Subsequently the exhaustive search technique was employed to find all combinations within the bounds identified by the GA that satisfied the desired LPSP. The combination with lowest life-time cost was taken as the optimal size of the HRES for the given demand. As the searching space of the iterative method can be reduced by the GA, the PV-module tilt angle $\left(\beta^{\circ}\right)$ and the WG installation height $(h)$ could also be included in the decision variables. 


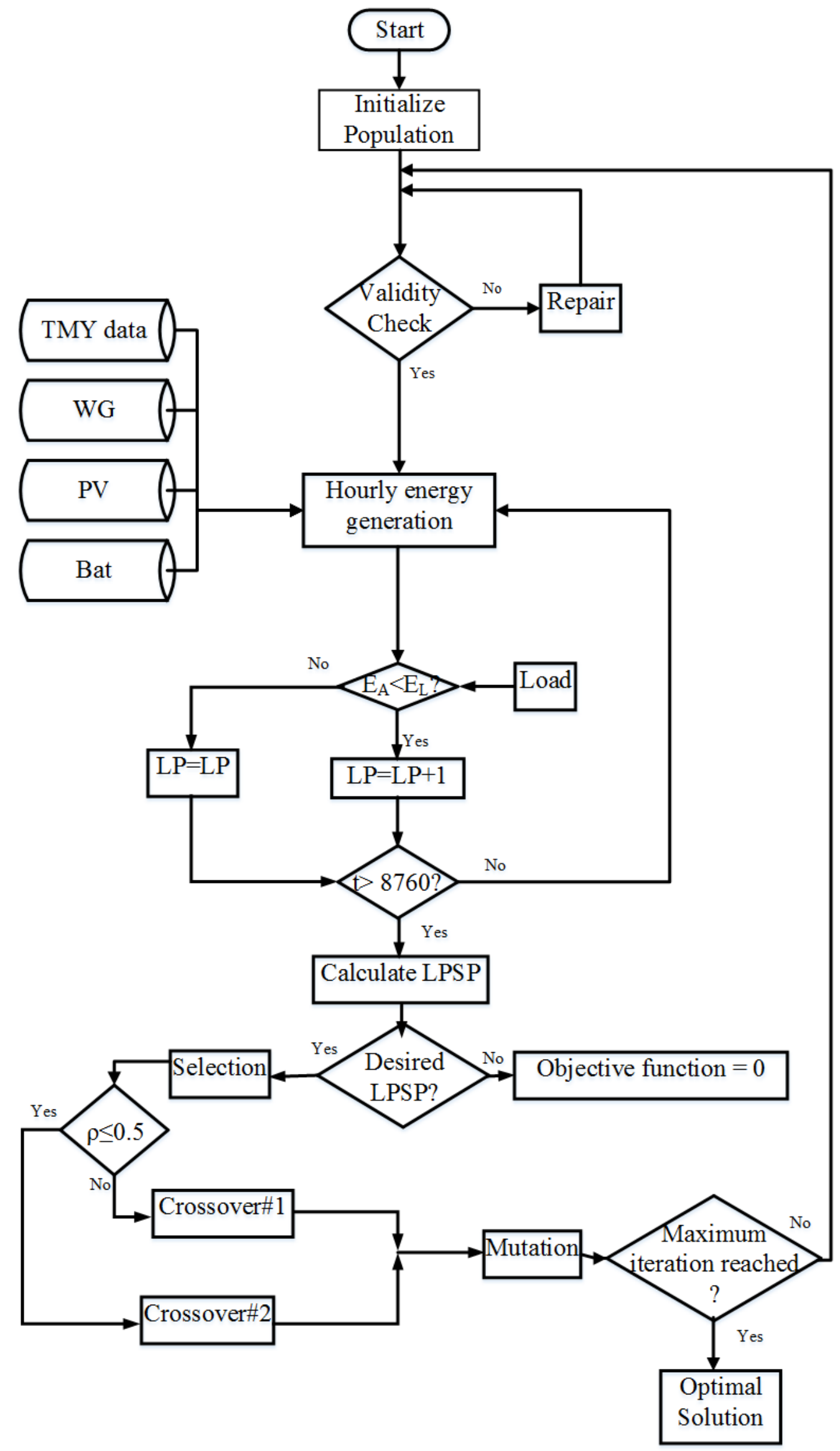

Fig. 4: Limited generation genetic algorithm 


\section{RESULTS AND DISCUSSION}

In order to demonstrate the hybrid optimization method, a HRES operating for a full year in Auckland, was sized for the "high night use" load profile. Several approximate optimal sizes for the HRES resulting from only 300 generations of the GA are shown in Table 4. Subsequently the bounds of the exhaustive search can be defined by the minimum and maximum values of the decision variables resulting from the approximate optimal sizes of a HRES suggested by the GA. In this respect, Table 5 shows the bounds of the variables taken from the results of Table 4. With the upper and lower limits of the decision variables defined by the GA, the exhaustive search method can find all feasible combinations relatively quickly.

TABLE 4. APPROXIMATE RESUlt WITH 300 GENERATIONS OF GA

\begin{tabular}{|c|c|c|c|c|c|}
\hline WG & PV & Battery & Height & Tilt angle & Total cost \\
$\#$ & $\#$ & $\#$ & $\mathbf{( m )}$ & $\mathbf{(}^{\mathbf{0}}$ & $\mathbf{( \$ )}$ \\
\hline 9 & 83 & $20(10 \times 2)$ & 27 & 53 & 374,680 \\
\hline 8 & 97 & $18(9 \times 2)$ & 34 & 70 & 356,290 \\
\hline 16 & 94 & $18(9 \times 2)$ & 24 & 76 & 372,710 \\
\hline 12 & 103 & $18(9 \times 2)$ & 16 & 55 & 395,920 \\
\hline 16 & 95 & $18(9 \times 2)$ & 15 & 57 & 376,520 \\
\hline
\end{tabular}

TABLE 5. BOUNDS OF DECISION VARIABLES

\begin{tabular}{|l|c|c|}
\hline Variable & Minimum & Maximum \\
\hline$N_{W G}$ & 8 & 16 \\
\hline$N_{P V}$ & 83 & 103 \\
\hline$N_{b a t}$ & $18(9 \times 2)$ & $20(10 \times 2)$ \\
\hline$\beta\left(^{\circ}\right)$ & 43 & 76 \\
\hline$h(\mathrm{~m})$ & 16 & 34 \\
\hline
\end{tabular}


As validation of the method, the optimized size of the HRES obtained by the hybrid method was cross referenced with the solutions obtained by a GA alone, as shown in Table 6. It is apparent from this that both these methods provide the same size HRES for the given load profile, thus demonstrating their capability. However, as the hybrid optimization method obtained the optimal size within a smaller number of iterations and so was used for optimal sizing of the HRES for all usage profiles.

TABLE 6. OPTIMAL SIZE OF A HRES USING HYBRID METHOD AND GA FOR HIGH NIGHT USE

\begin{tabular}{|l|c|c|c|c|c|c|}
\hline \multicolumn{1}{|c|}{ Method } & WG & PV & Battery & Height & Tilt angle & Total cost \\
& $\#$ & $\#$ & $\#$ & $(\mathbf{m})$ & $\left(\mathbf{(}^{\mathbf{0}}\right.$ & $\mathbf{( \$ )}$ \\
\hline GA & 8 & 97 & $18(9 \times 2)$ & 29 & 50 & 354,609 \\
\hline Hybrid & 8 & 97 & $18(9 \times 2)$ & 29 & 50 & 354,609 \\
\hline
\end{tabular}

\subsection{Optimal size considering socio-demographic factors}

To explore the effect of socio-demographic factors on the optimal sizing of a HRES with zero LPSP each of the load profiles shown in Fig. 2, and an average of all profiles, was analyzed for a full year of operation during an Auckland TMY, the results of which are shown in Table 7.

TABLE 7. OPTIMIZED SIZE OF A HRES FOR EACH LOAD PROFILE

\begin{tabular}{|l|c|c|c|c|c|c|}
\hline \multicolumn{1}{|c|}{ Load Profile } & WG & PV & Battery & Height & Tilt angle & Total cost \\
& $\#$ & $\#$ & $\#$ & $(\mathbf{m})$ & $(\mathbf{0})$ & $\mathbf{( \$ )}$ \\
\hline High night use & 8 & 97 & $18(9 \times 2)$ & 29 & 50 & 354,609 \\
\hline Morning and evening peaks & 4 & 77 & $14(7 \times 2)$ & 29 & 45 & 267,895 \\
\hline Flat day use & 6 & 95 & $14(7 \times 2)$ & 34 & 27 & 291,175 \\
\hline Evening peak use & 4 & 110 & $14(7 \times 2)$ & 30 & 20 & 293,407 \\
\hline Low flat use & 4 & 65 & $12(6 \times 2)$ & 28 & 50 & 231,798 \\
\hline Low use with evening peak & 4 & 62 & $12(6 \times 2)$ & 29 & 51 & 228,894 \\
\hline Average & 6 & 75 & $14(7 \times 2)$ & 32 & 54 & 275,310 \\
\hline
\end{tabular}


An inspection of these results shows up several important considerations regarding the optimal size of a HRES and the demand profile. In particular, it is important to note that by sizing a system based on an "Average" load profile, systems could be oversized and unnecessarily expensive for a number of users, particularly those with low use profiles. In this regard, it can be seen that the optimal size for the "Low flat use" and "Low use with evening peak" profiles are almost the same due to the similarity in magnitude and distribution of the load. This oversizing is further exasperated if the system is sized on the basis of a "High night use" profile.

The "Evening peak use" profile has a small morning peak, low midday use and a high evening peak, the outcome of which is that the number PV modules and batteries increases significantly from the "Low use" profiles. On the other hand, the "Flat day use" profile exhibits a flat high day use with a slight morning peak that gradually reduces through the afternoon, before a moderate evening peak. This causes a significant change in the proportion of both WGs and PV modules in the optimum sizing, as the solar radiation in the early morning and evening is low, meaning the demand is satisfied with an increased number of WG. A similar outcome is observed in case of "high night use" profile, where the loading is principally night based, with low loading during the day. Thus, it is clear from the analysis that higher evening and night demand requires more WGs whereas higher morning and midday demand is satisfied by increasing the number of PV modules.

To illustrate this point further, the Pearson's correlation coefficient between hourly load and the average hourly solar radiation and wind speed for each of demand the profiles was determined, as shown in Table 8 . 
TABLE 8. CORRELATION BETWEEN HOURLY SOLAR RADIATION AND WIND SPEED FOR EACH LOAD PROFILE

\begin{tabular}{|l|c|c|}
\hline \multicolumn{1}{|c|}{ Load Profile } & $\begin{array}{c}\text { Pearson's Coefficient } \\
\text { with solar radiation }\end{array}$ & $\begin{array}{c}\text { Pearson's Coefficient with } \\
\text { wind speed }\end{array}$ \\
\hline High night use & -0.735 & -0.736 \\
\hline Morning and evening peaks & -0.253 & -0.149 \\
\hline Flat day use & 0.536 & 0.460 \\
\hline Evening peak use & -0.277 & -0.108 \\
\hline Low flat use & 0.278 & 0.465 \\
\hline Low use with evening peak & -0.211 & -0.042 \\
\hline
\end{tabular}

It is evident from the Pearson's correlation coefficient values that the "high night use" profile shows a strong negative correlation with the solar radiation and wind speed of the site. From this it can be inferred that, for heavy night usage the storage size needs to be increased significantly to meet the load, as was borne out by the optimization. On the other hand, for loads exhibiting a positive correlation, such as the "flat day use" profile, the solar and wind require less storage capacity as the instantaneous generation can satisfy much of the demand.

Now a key consideration of optimizing a HRES with respect to socio-demographic factors is in understanding how a system sized for one class of user responds to the demands from another class of user, for instance if there is transfer of ownership of the system. Therefore, a cross comparison of the LPSP was undertaken for each system operating with other load profiles as shown in Table 9. 
TABLE 9. CROSS LPSP VALUES WITH OPTIMIZED SYSTEM FOR EACH CLASS

\begin{tabular}{|l|c|c|c|c|c|c|}
\hline \multicolumn{1}{|c|}{ System for Profile } & \multicolumn{5}{|c|}{ LPSP(\%) for } \\
\cline { 2 - 7 } & $\begin{array}{c}\text { High } \\
\text { night use }\end{array}$ & $\begin{array}{c}\text { Morning } \\
\text { and } \\
\text { evening } \\
\text { peaks }\end{array}$ & $\begin{array}{c}\text { Flat day } \\
\text { use }\end{array}$ & $\begin{array}{c}\text { Evening } \\
\text { peak use }\end{array}$ & $\begin{array}{c}\text { Low flat } \\
\text { use }\end{array}$ & $\begin{array}{c}\text { Low use } \\
\text { with } \\
\text { evening } \\
\text { peak }\end{array}$ \\
\hline High night use & 0.00 & 0.00 & 0.00 & 0.00 & 0.00 & 0.00 \\
\hline Morning and evening peaks & 1.83 & 0.00 & 0.39 & 0.27 & 0.00 & 0.00 \\
\hline Flat day use & 0.57 & 0.00 & 0.00 & 0.01 & 0.00 & 0.00 \\
\hline Evening peak use & 0.50 & 0.00 & 0.01 & 0.00 & 0.00 & 0.00 \\
\hline Low flat use & 3.97 & 0.32 & 2.11 & 1.78 & 0.00 & 0.00 \\
\hline Low use with evening peak & 4.52 & 0.55 & 2.75 & 2.28 & 4.00 & 0.00 \\
\hline
\end{tabular}

From this it is found that only the optimized system for "high night use" profile could provide a zero LPSP for all loading conditions. However, such a system significantly increases the cost by trying to satisfy the highest night use and lower day use profile compared to the cost of other classes. Conversely, the optimized size for "Flat day use" and "Evening peak use" show good performance in meeting the conditions of all classes with moderate system cost. 


\section{CONCLUSION}

From the results shown in this work it is apparent that greater consideration must be made of sociodemographic factors in optimally sizing stand alone hybrid renewable energy systems. From the six types of electricity users identified it was found that the optimal sized system for one user cannot necessarily satisfy a different user of with zero loss of power supply probability unless the system becomes larger (more generation and storage) and therefore more costly. In this respect the cost is influenced significantly by the magnitude and temporal positions of the peak demand. Furthermore, the temporal position and duration of the peak demand and their relationship to the availabilty of wind and solar radiation should be taken into account in order to find the optimal size of HRES.

Thus, it is suggested that the HRES size that minimizes the total system cost as well as the unmet demand with all the classified socio-demographic load profiles of the site for a desired reliability can be considered as an overall optimum. However, by optimizing with consideration to the owners socio-demographic profile, borne out by the nature of their electricity usage, the system cost can be reduced.

\section{REFERENCES}

Ai, B., Yang, H., Shen, H., Liao, X., 2003. Computer-aided design of PV/wind hybrid system. Renew. Energy 28, 1491-1512. doi:10.1016/S0960-1481(03)00011-9

Aissou, S., Rekioua, D., Mezzai, N., Rekioua, T., Bacha, S., 2015. Modeling and control of hybrid photovoltaic wind power system with battery storage. Energy Convers. Manag. 89, 615-625. doi:10.1016/j.enconman.2014.10.034

Baniasad Askari, I.., Baniasad Askari, L.., Kaykhah, M.M.., Baniasad Askari, H.., 2014. Optimisation and techno-economic feasibility analysis of hybrid (photovoltaic/wind/fuel cell) energy systems in Kerman, Iran; considering the effects of electrical load and energy storage technology. Int. J. Sustain. Energy 33, 635-649. doi:10.1080/14786451.2013.769991 
Borowy, B.S., Salameh, Z.M., 1996. Methodology for optimally sizing the combination of a battery bank and PV array in a Wind/PV hybrid system. IEEE Trans. Energy Convers. 11, 367-373. doi: $10.1109 / 60.507648$

Borowy, B.S., Salameh, Z.M., 1994. Optimum photovoltaic array size for a hybrid wind/PV system. IEEE Trans. Energy Convers. 9, 482-488. doi:10.1109/60.326466

Chedid, R., Akiki, H., Rahman, S., 1998. A decision support technique for the design of hybrid solar-wind power systems. IEEE Trans. Energy Convers. 13, 76-83. doi:10.1109/60.658207

U.S. Department of Energy, 2013. Weather data [WWW Document]. URL http://apps1.eere.energy.gov/buildings/energyplus/weatherdata.about (accessed 1.30.13).

Deshmukh, M.K., Deshmukh, S.S., 2008. Modeling of hybrid renewable energy systems. Renew. Sustain. Energy Rev. 12, 235-249. doi:10.1016/j.rser.2006.07.011

Diaf, S., Belhamel, M., Haddadi, M., Louche, A., 2008. Technical and economic assessment of hybrid photovoltaic/wind system with battery storage in Corsica island. Energy Policy 36, 743-754. doi:10.1016/j.enpol.2007.10.028

González, A., Riba, J., Rius, A., Puig, R., 2015. Optimal sizing of a hybrid grid-connected photovoltaic and wind power system, Applied Energy 154, 752-762. doi:10.1016/j.apenergy.2015.04.105

Gupta, R.A., Kumar, R., Bansal, A.K., 2012. Wind / Photovoltaic Hybrid Energy System using Genetic Algorithm, in: 2012 International Conference on Computing, Communication and Applications. Tamilnadu, pp. 1-6. doi:10.1109/ICCCA.2012.6179189

Hong, Y., Member, S., Lian, R., 2012. Optimal Sizing of Hybrid Wind / PV / Diesel Generation in a StandAlone Power System Using Markov-Based Genetic Algorithm IEEE Trans.on Power Delivery 27, 640647.

Kaabeche, A., Belhamel, M., Ibtiouen, R., 2011. Sizing optimization of grid-independent hybrid 
photovoltaic/wind power generation system. Energy 36, 1214-1222. doi:10.1016/j.energy.2010.11.024

Kellogg, W.D., Nehrir, M.H., Venkataramanan, G., Gerez, V., 1998. Generation unit sizing and cost analysis for stand-alone wind, photovoltaic, and hybrid wind/PV systems. IEEE Trans. Energy Convers. 13, 7075. doi:10.1109/60.658206

Kohonen, T., 1989. Self-Organization and Associative Memory, Self Organization and Associative Memory. doi:10.1007/978-3-642-88163-3

Koutroulis, E., Kolokotsa, D., Potirakis, A., Kalaitzakis, K., 2006. Methodology for optimal sizing of standalone photovoltaic/wind-generator systems using genetic algorithms. Sol. Energy 80, 1072-1088. doi:10.1016/j.solener.2005.11.002

Ma, T., Lashway, C.R., Song, Y., Mohammed, O., 2014. Optimal renewadble energy farm and energy storage sizing method for future hybrid power system, in: 2014 17th International Conference on Electrical Machines and Systems, ICEMS 2014. pp. 2827-2832. doi:10.1109/ICEMS.2014.7013979

Rouhani, A., Kord, H., Mehrabi, M., 2013. A comprehensive method for optimum sizing of hybrid energy systems using intelligence evolutionary algorithms. Indian J. Sci. Technol. 6, 4702-4712. doi:10.1016/j.enconman.2010.09.028

Stoecklein, A., Pollard, A., Camilleri, M., Tries, J., Isaacs, N., 2001. The Household Energy End-Use Project: Measurement Approach and Sample Application of the New Zealand Household Energy Model. CIB World Build. Congr.

Tégani, I., Aboubou, A., Ayad, M.Y., Becherif, M., Saadi, R., Kraa, O., 2014. Optimal sizing design and energy management of stand-alone photovoltaic / wind generator systems. Energy Procedia 50, 163170. doi:10.1016/j.egypro.2014.06.020

Tito, M., Lie, T., Anderson, T., 2013. Sizing Optimization of Wind-Photovoltaic Hybrid Energy Systems under Transient Load. Int. J. Power Energy Syst. 33, 168-174. 
Yang, H., Lu, L., Zhou, W., 2007. A novel optimization sizing model for hybrid solar-wind power generation system. Sol. Energy 81, 76-84. doi:10.1016/j.solener.2006.06.010

Yang, H., Zhou, W., Lu, L., Fang, Z., 2008. Optimal sizing method for stand-alone hybrid solar-wind system with LPSP technology by using genetic algorithm. Sol. Energy 82, 354-367. doi:10.1016/j.solener.2007.08.005

Zhou, W., Lou, C., Li, Z., Lu, L., Yang, H., 2010. Current status of research on optimum sizing of stand-alone hybrid solar-wind power generation systems. Appl. Energy 87, 380-389. doi:10.1016/j.apenergy.2009.08.012 